\title{
Evolución histórica de la criminología en el derecho penal
}

\section{Historical evolution of criminology in criminal law}

Jeraldin Carolina España Vidal

Maestría en Derecho Constitucional

Universidad de San Carlos de Guatemala

jeraldinesvidal@outlook.com

Recibido: 28/06/2021

Aceptado: 15/08/2021

\section{Referencia del artículo}

España Vidal , J. C. (2021). Evolución histórica de la criminología en el derecho penal. Revista Diversidad Científica, 1(1). 85-95.

\section{Resumen}

\section{DOl:https://doi.org/10.36314/diversidad.v1i1.10}

La Evolución histórica de la Criminología en el Derecho Penal, la podemos ver reflejada en tres fases. La primera fase de la criminología como tal, la encontramos en su etapa pre científica, esta se divide en dos direcciones que se diferencian claramente, la primera es la que se puede llamar "clásica" (esta con el fin de comprender el inicio de la existencia ideológica de la Criminología, fruto de las doctrinas, de los reformadores del derecho penal clásico) la segunda la que es calificada de experimental por tener una variedad de investigaciones sobre el crimen, usadas por expertos de las diversas materias; (antropólogos, psiquiatras, frenólogos, fisonomistas, etc.) teniendo todos un mismo objetivo. En la segunda es la etapa científica de la criminología encontramos el imperio del positivismo en sentido exacto. Y cuando se estudia al positivismo, es necesario definir al método científico, siendo este la metodología experimental de las ciencias naturales. Desde esta figura se tratan los fenómenos sociales. Los fundadores y más ilustres representantes de la Escuela Positivista son LOMBROSO, GARAFOLO Y FERRI. Y la tercera denominada la moderna Criminología, en donde la lucha de la Escuela Clásica y Escuela Positivista de los siglos XVIII y XIX, creó un importante imperio en las proposiciones criminológicas, político-criminales y penales del siglo $\mathrm{XX}$. Consecuencia de esa disputa fue la definición de tres disposiciones criminológicas: las sociológicas, las biológicas y las psicológicas.

Palabras clave: evolución, criminología, derecho penal 


\begin{abstract}
The historical Evolution of Criminology in Criminal Law, we can see it reflected in three phases. The first phase of criminology as such, we find it in its pre-scientific stage, this is divided into two directions that are clearly differentiated, the first is what can be called "classical" (this in order to understand the beginning of the ideological existence of Criminology, the result of doctrines, of the reformers of classical criminal law) the second which is described as experimental because it has a variety of investigations on crime, used by experts in various subjects; (anthropologists, psychiatrists, phrenologists, physiognomists, etc.) all having the same objective. In the second is the scientific stage of criminology we find the empire of positivism in the exact sense. And when positivism is studied, it is necessary to define the scientific method, this being the experimental methodology of the natural sciences. From this figure social phenomena are treated. The founders and most illustrious representatives of the Positivist School are LOMBROSO, GARAFOLO AND FERRI. And the third called modern Criminology, where the struggle of the Classical School and Positivist School of the 18th and 19th centuries, created an important empire in the criminological, political-criminal and penal propositions of the 20th century. The consequence of this dispute was the definition of three criminological provisions: sociological, biological and psychological.
\end{abstract}

Keywords: evolution, criminology, criminal law 


\section{Introducción}

La Evolución historia de la criminología y el derecho penal no solo es interesante, sino que establece un cierto tipo de conocimientos que es preciso para la preparación de un experto en la materia penal. No se puede dejar a un lado este punto de vista, pues reflejaríamos una formación de aparentes expertos; en otras palabras, arrojaríamos al planeta unos reservados tramitadores de causas, que no tienen conciencia de cuál es su función real. El objetivo del presente artículo, es adquirir conocimientos referentes a la Evolución de la Criminología en el Derecho Penal, hasta la actualidad y obtener la capacidad de crítica de dichos conocimientos.

Es por ello que la Evolución histórica de la Criminología en el Derecho Penal, la podemos ver reflejada en tres fases. La primera fase de la criminología como tal, la encontramos en su etapa pre científica, esta se divide en dos direcciones que se diferencian claramente, la primera es la que se puede llamar "clásica" (esta con el fin de comprender el inicio de la existencia ideológica de la Criminología, fruto de las doctrinas, de los reformadores del derecho penal clásico) la segunda la que es calificada de experimental por tener una variedad de investigaciones sobre el crimen, usadas por expertos de las diversas materias; (antropólogos, psiquiatras, frenólogos, fisonomistas, etc.) teniendo todos un mismo objetivo. Y la tercera denominada la moderna Criminología en la cual se definen tres disposiciones criminológicas: las sociológicas, las biológicas y las psicológicas.

\section{Contenido \\ 1. Etapa Pre-cientifica \\ 1.1 Escuela Clásica}

Un tema debatido es si la escuela clásica puede ser considerada una escuela de la criminología. Si se estudiaren las teorías de la criminología como las que experimentan el origen del comportamiento delictivo, quizás la escuela clásica no figuraría entre ellas, por motivo de que sus autores se centraron principalmente en el estudio de cómo tendría que ser el Derecho penal (Larrauri, 2001).

La aportación de la escuela clásica a la criminología, se ha elegido por explicar, porque, se opina que cuando tácitamente, la escuela clásica si provee una definición de la conducta delictiva y, también, las teorías criminológicas no sólo estudian la conducta del individuo que quebranta una norma sino los medios con los que se rebela ante esta infracción (Larrauri, 2001). 
En la Escuela Clásica en criminología, los actores más importantes Beccaria y Benthan.

\subsubsection{Con relación a Beccaria}

Para Orellana Wiarco, considera que, en relación a Beccaria, su famoso libro "De los Delitos y las Penas" escrita en latín, después de su éxito rotundo fue traducida en varios idiomas, esta pequeña obra conmovió en sus cimientos, al mundo intelectual de su época, pues al leer dicha obra se puede consignar las siguientes reflexiones que han tenido mayor impacto dentro de las Escuelas Criminológicas (Wiarco, 1999).

La primera reflexión es que el fin de las penas es salvaguardar el orden social impidiendo la ejecución de las infracciones. Lo que fundamenta el derecho de sancionar del ente soberano es por la importancia de prevenir los delitos y la pena, siendo esto eficaz para impedir el cometido de delitos ya que el placer y el sufrimiento son los motores de la labor humana (Larrauri, 2001).

La segunda reflexión significativa procedente de BECCARIA y que interviene en las siguientes teorías criminológicas es la imagen del hombre. "Manifiesta Beccaria, infaliblemente si el castigo es útil, es a causa de que el hombre está en la facultad de pensar de confrontar lo que beneficia del delito con el valor de la pena". En efecto surge la supuesta imagen de que todos los hombres poseen esta facultad de meditación. Asimismo, se prevé que el coste-beneficio será el que determine en la acción humana. La imagen de una persona racional y hedonista es de un "hombre económico".

La tercera reflexión sustancial de BECCARIA es la controversia sobre las características que le corresponden tener a las penas para ser eficientes en su lucha contra el delito. Si se quiere que las penas sean preventivas corresponde asignar en opinión de BECCARIA "Con Prisa" no sólo para impedir poseer a la persona encerrada en espera de juicio, sino porque cuanto antes se impone la pena, más rápido se graba en la mente del individuo la asociación de que a todo beneficio fruto del delito le persigue una consecuencia de la pena. BECCARIA establece que las penas también corresponden ser "Certeras" porque "No es la crueldad de las penas uno de los grandes frenos de los delitos, sino la certidumbre del castigo unido con la esperanza de la impunidad.

Y la cuarta reflexión de BECCARIA se puede señalar "Que deben de tener severidad las pena" esto es el mal simbolizado por lo que se espera obtener del delito, 
las penas deben estar dotadas de una determinada dureza", "Pero también este es su límite superior pues en cualquier pena que exceda el mínimo preciso para impedir los delitos es una pena cruel por excesiva. Por la sanción debe ser el mínimo necesario para compensar las ganancias del delito. En síntesis, se puede concluir que las meditaciones de BECCARIA influyeron en investigaciones criminológicas en la tentativa de constreñir qué variable influye más en aras de prevenir delitos.

\subsubsection{Con Relación A Bentham}

El segundo autor representante de la Escuela clásica de la Criminología, es BENTHAM, se puede expresar que este autor fue un prolífico, pues a él se le considera como el fundador del utilitarismo, sus ideas muy reñidas consiguieron una evolución legislativa que alcanzó ciertas medidas de representación criminológica, estas fueron las medidas preventivas de los delitos, diseña además un cuadro de los sustitutivos penales, llevándole la delantera a Ferri, no obstante es más popular en este campo por el estudio de una cárcel ideal que llamó Panoptico (Larrauri, 2001) en la que debe dominar, el estudio, el trabajo, la paz y el orden, para lograr la readaptación social de los delincuentes (Wiarco, 1999).

Sus reflexiones acerca de las penas pueden encontrarse dispersas en "An Introduction to the Principles of Morals and Legislation" que debía servir como introducción para el código penal inglés. Las principales aportaciones de este autor la encontramos en sus siguientes reflexiones:

BEHTHAM, señala en la primera reflexión que para "EL fin común que todas las leyes debieran tener, es acrecentar la felicidad general de la comunidad y, por supeditado a esto exceptuar, como sea posible cualquier cosa que trate de disminuir esta felicidad. Pero todo castigo es un dato, todo castigo es un mal. Conforme al principio de utilidad, si se admite el castigo en algún caso, sólo puede existir en caso de que prometa prescindir un mal mayor (JEREMY, 1982).

BENTHAM señala que "La prevención general debiera ser el fin primordial de la sanción, su verdadera justificación. Si consideramos el delito ejecutado a manera de un hecho abandonado que difícilmente se volverá a repetir el castigo sería inútil sólo sería añadir un mal a otro. Pero, si se considera que el delito impune desiste el camino abierto no sólo al mismo delincuente, sino también a todos aquellos que tienen los mismos oportunidades y motivos para llevarlo a cabo percibimos que el castigo infringido a la persona es una fuente de seguridad para todos. (Larrauri, 2001). 
En síntesis, logramos ratificar que estas meditaciones tienen una preeminencia para el Derecho Penal y la Penología, creemos que existieron también importantes en conformar la agenda de la investigación criminológica. Precisamente si la criminología consigue manifestar, mediante sus investigaciones prácticas, que la sanción de determinada conducta no es eficaz, y no consigue que se pueda prevenir delitos mostrando la presencia de otros medios más eficaces y menos ofensivos para prevenirlos, entonces, la sanción de esta conducta de acuerdo a BENTHAM carece de Justificación.

\section{Etapa Científica \\ 2.1 Escuela Positivista}

La Escuela Positiva del Derecho Penal nace como una reacción contra el clasicismo liberal, proporcionando al Derecho un argumento antropológico, trasladando el criterio restrictivo basado en la valoración de la objetividad del delito, y supliéndolo por la predominante apreciación de la personalidad del actor (Cuello Calón, 1975), desde el inicio de la habitual comprobación de la incapacidad del sistema penal hasta entonces vigente, en orden a la baja criminalidad (Fontán Balestra, $1970)$.

Los autores y más ilustres representantes de esta escuela, a quienes llegó a nombrarse "LOS EVANGELISTAS" (Cuello Calón, 1975) fueron CESARE LOMBROSO (EI Médico), RAFAELE GAROFALO (El Jurista) y ENRICO FERRI (EI Sociólogo), según lo consigna JIMENEZ DE ASUA (Jíménez de Asúa, 1979)

Pero de las variedades existentes entre cultores diversos, se dice que la Escuela Positiva se caracteriza por principios totalmente opuestos, por no decir que incompatibles, a los que distinguían a la Escuela Clásica.

Según LOMBROSO (Lozano y Lozano, 1979), el delito, es un fenómeno social y natural que es producido por causas orden social, físico y biológico, y el delito, es un algo natural como los nacimientos, los cambios de temperatura y las muertes y se considera que concluye que no es un fenómeno propio del hombre, ya que también se encuentra en los reinos animal y vegetales. Si se califica un hecho como delito es porque obstruye las costumbres y los usos de un país y de una época (Vilar, 1939) siendo superfluo, en consecuencia, sería darle al delito un carácter moral que no podría tener. 
Fue GAROFALO (Peláez Vargas, 1981) quien elaboró la popular definición "natural" del delito, "estableciéndola como la lesión de alguna parte del sentido moral que consiste en los sentimientos generosos fundamentales, es decir, los propiedad y de piedad, en media que se hallan en la sociedad, a través de acciones nocivas para la población", recibió tan duras críticas aún por parte de los propios positivistas, como el propio FERRI (Ferri, 1933), por no comprender las emociones de piedad y de probidad del conjunto de hombres. La teoría de la "Defensa Social" no reflejaba bastante el punto de vista subjetivo para evidenciar oportunamente la responsabilidad jurídico penal, RAFAEL GAROFALO elaboró la teoría de la "Temibilidad", a la que llamó como "la vileza firme y activa del delincuente y la cantidad de mal previsto que hay que temer por parte del mismo delincuente" (Fontán Balestra, 1970).

Debemos de recordar en cuanto al criterio de responsabilidad penal, cómo FERRI desde su tesis doctoral negó la existencia del "Libre Albedrío" considerando que tal noción no era más que un delirio: Constante con tal posición, FERRI introdujo la tesis del "Determinismo", con la cual el individuo no puede evitar de las leyes universales de causalidad que se consuman en el mundo en el orden biológico, físico, y psicológico (Mesa Velásquez, 1979).

Aun así, FERRI anhelaba suprimir la palabra "Pena" del lenguaje científico, y del cuadro carcelario las medidas expiatorias inspiradas en el instinto a hacer sufrir al delincuente: Hay aceptar que FERRI intentaba cambiar la noción de "pena" y, así también, el de "retribución", por el de "sanción", con un contenido de forma para adaptar y educar al delincuente. A lo largo de la historia las penas tenían certificado y demostrado su inutilidad, FERRI pensaba que más transcendentales que las penas eran los "Sustantivos Penales", que no existirían más que los numerosos expedientes de orden civil, económico, científico, político, religioso, familiar y educativo que tiene como objeto la prevención evasiva de la delincuencia, es decir, que tienden a la eliminación anticipada de los cambiadísimos factores criminógenos (Rodríguez Manzanera, 1984).

Hay que recordar que los Positivistas crearon una clasificación de los delincuentes, que en un inicio estuvo perfilada por LOMBROSO sobre las clases de "Delincuente Nato" y del "Loco Moral", y a la que después FERRI encajó algunas variedades, añadiendo las categorías de delincuentes pasionales, ocasionales y habituales (Mesa Velásquez, 1979). La categoría de "Delincuentes Nato" fue estructurada por LOMBROSO a partir de la investigación efectuada en el cadáver del bandido VILELLA, hacia el año de 1870, en dicho cráneo halló lo que él nombró "toseta occipital media" y que es extrañísimo hallar en el hombre, siendo habitual, en animales inferiores como los peces, de tal suerte que, investigando las diferencias entre el loco y el delincuente, encontró esto que fue su coincidencia, en la medida en que la persona 
delincuente imitaba al salvaje, en verdadera semejanza que a veces se remontaba, en la nivel zoológico, a los seres prehumanos (Jíménez de Asúa, 1979).

\section{La Moderna Criminología}

Y la tercera denominada la moderna Criminología, en donde la lucha de la Escuela Clásica y Escuela Positivista de los siglos XVIII y XIX, creó un importante imperio en las proposiciones criminológicas, político-criminales y penales del siglo XX. Consecuencia de esa disputa fue la definición de tres disposiciones criminológicas: las sociológicas, las biológicas y las psicológicas.

La disposición biológica, vuelve a la explicación del delito desde la figura del delincuente, en la cual se intenta buscar el elemento que diferencia su conducta. Este modelo criminológico inicia de la premisa de que el delincuente es un ser anormal y distinto, ha esto se le denomino principio positivista de la diversidad. Lo que pretende estos modelos es explicar científicamente la no generalidad del delito en un conjunto de individuos supuestamente iguales. GARCÍA PABLOS, señala que tratan de decir por qué el crimen se distribuye de forma no semejante, centrándose en muy pequeños grupos humanos, dichas personas retienen significativamente el cometido de la mayor parte de los delitos (Garcia Pablos, 2001).

La disposición psicológica, pretende manifestar la conducta delictiva de las personas en función de determinados procesos psíquicos patológicos o normales. Es por ello que se debe diferenciar la psicología, como estudio de la conducta humana, señalando los factores y variables que hacen figurar en él; la psiquiatría o psicopatología, que estudia desordenes de personalidad de carácter patológicos, es decir, desórdenes mentales y sus expresiones; y, el psicoanálisis, que pretende buscar respuestas del comportamiento humano en el inconsciente, por medio del análisis introspectivo (Garcia Pablos, 2001).

La disposición sociológica se manifestó desde el inicio de la criminología. En Italia, Ios autores Lombroso, Enrique Ferri, y en Francia Gabriel Tarde, acentuaban la importancia del aprendizaje y del medio o de la copia en la noción de la criminalidad. El sociólogo considera que, en el medio ambiente sociocultural, el acto criminal como la respuesta de ciertas personas a las provocaciones moduladas por la organización social. Durkheim ha manifestado de un modo sumario la orientación sociológica: el crimen es para él, y no para una entidad jurídica ni una biopsicológica; únicamente es criminal el individuo que la conciencia colectiva de un conjunto de 
personas lo califica así. Una sociedad que es dominada por el valor concedido a la propiedad privada concretará como prototipo de criminal al ladrón (SZABO, 1980).

\section{Conclusión}

La evolución histórica de la Criminología en el derecho penal se ve reflejada en tres etapas en las cuales hubo importantes descubrimientos. Es por ello que en la etapa precientífica de la historia de la criminología denominada escuela clásica, emparentada a los elementos de la llustración, se creó la igualdad de los seres humanos y se protegió la supremacía del conocimiento sobre el dogma, que afirmaba que todos los individuos podían actuar responsablemente.

La criminología en el siglo XIX, empezó a formarse como una disciplina científica, denominándose escuela positivista, la cual pensaba que el comportamiento humano, inclusos los crímenes, eran consagrados por sus características innatas.

En el siglo XX, en la etapa moderna, la criminología comenzó a ampliarse aumentando el campo de estudio y se incluyeron diversas materias, se originó un cambio gigantesco en el modelo de la criminología. Desde ese momento, se empezó a vigilar en cómo el delincuente alcanzaba a serlo, dentro del ambiente social y su contacto con las víctimas.

Aunque el fenómeno delictivo no se va erradicar de la tierra, considero que la evolución de la criminología en el siglo XXI tiene aspectos relevantes al ampliar su estudio a la víctima o agraviado del delito, los delitos de crimen organizado, el derecho penal internacional, terrorismo, lavado de dinero y blanqueo de capitales, entre otros, que cambian su tradicional modelo de prevención general transformándose en políticas o modelos de seguridad y pública que incluye medidas represivas para garantizar la ley y el orden social.

\section{Declaración}

El estudio se realizó de acuerdo al Código de Ética y Buenas Prácticas COPE. 
Revista Diversidad Científica Vol. 1 No. 1 Año 2021

\section{Conflicto de intereses}

La autora declara no tener ningún conflicto de intereses.

\section{Referencias}

Cuello Calón, E. (1975). Derecho Penal. México D.F.: Editora Nacional.

Ferri, E. (1933). Principios de Derecho Críminal (Vol. 168 de Biblioteca Jurídica de Autores Españoles y Extranjeros (s.p.c.)). Madrid: Reus.

Fontán Balestra, C. (1970). Tratado de Derecho Penal (2da. edición ed.). Buenos Aires: Editorial Ablodo-Perrot.

Fontán Balestra, C. (1970). Tratado de Derecho Penal. (3era. edicion ed.). Buenos Aires: Editorial Ablodo-Perrot.

Garcia Pablos, A. (2001). Criminologia una Introducción a sus Fundamentos Teóricos para Juristas (4ta. Edicion ed.). Valencia: Tirant lo Blanch.

Jeremy, B. (1982). "An Introducción to the principles of Morals and Legislation". Londres: Methuen.

Jíménez de Asúa, L. (1979). La Ley y el Delito (9na, Edicion ed.). Buenos Aires: Editorial Sudamericana.

Larrauri, J. C. (2001). Teorías Criminologicas. Barcelona, España: Bosh, S.A.

Lozano y Lozano, C. (1979). Elementos de Derecho Penal (3era. Edición ed.). Bogota: Temis.

Mesa Velásquez, L. E. (1979). Lecciones de Derecho Penal. Bogota: Universidad de Estemaso de Colombia. 
Peláez Vargas, G. (1981). Manual de Derecho Penal General. (1era. Edición ed.). Medellín: Editorial Bedout.

Rodríguez Manzanera, L. (1984). Criminología. (4ta. edición ed.). México. D.F.: Porrúa.

Szabo, D. (1980). “Criminología y política en materia criminal”. México: Siglo XXI.

Vilar, E. (1939). El Nuevo Código Penal y Modo de Interpretarlo Científicamente. Bogotá: Librería Colombia.

Wiarco, O. (1999). Manual de la Criminología. México: Porrúa.

\section{Sobre la autora \\ Jeraldin Carolina España Vidal}

Licenciada en Ciencias Jurídicas y Sociales, Abogada y Notaria, egresada del Centro Universitario de Oriente de la Universidad de San Carlos de Guatemala, con Maestría en Derecho Constitucional, ha realizado investigaciones del procedimiento de protección de la mujer embarazada menor de catorce años y la obligación estatal de asistencia, tesis impresa en septiembre 2016. Tesis de Maestría titulada la Soberanía y derecho internacional, Caso de Guatemala.

Copyright (c) Jeraldin Carolina España Vidal

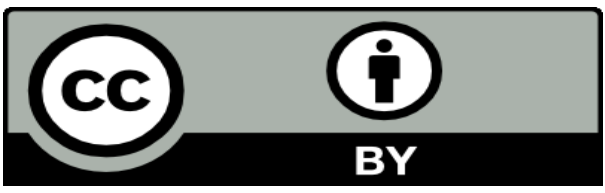

Este texto está protegido por una licencia CreativeCommons 4.0.

Usted es libre para compartir, copiar y redistribuir el material en cualquier medio o formato y adaptar el documento, remezclar, transformar y crear a partir del material para cualquier propósito, incluso comercialmente, siempre que cumpla la condición de atribución: usted debe reconocer el crédito de una obra de manera adecuada, proporcionar un enlace a la licencia, e indicar si se han realizado cambios. Puede hacerlo en cualquier forma razonable, pero no de forma tal que sugiera que tiene el apoyo del licenciante o lo recibe por el uso que hace. 